\title{
Diversity of methanogens in ruminants in Queensland
}

\author{
D. Ouwerkerk ${ }^{\mathrm{A}, \mathrm{B}}$, A. F. Turner ${ }^{\mathrm{A}, \mathrm{B}}$ and A. V. Klieve $\mathrm{A}^{\mathrm{A}, \mathrm{B}, \mathrm{C}}$

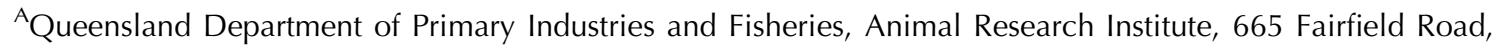 \\ Yeerongpilly, Qld 4105, Australia. \\ ${ }^{B}$ The Cooperative Research Centre for Beef Genetic Technologies, University of New England, Armidale, \\ NSW 2351, Australia. \\ ${ }^{\mathrm{C}}$ Corresponding author. Email: athol.klieve@dpi.qld.gov.au
}

\begin{abstract}
Methane emissions from ruminant livestock represent a loss of carbon during feed conversion, which has implications for both animal productivity and the environment because this gas is considered to be one of the more potent forms of greenhouses gases contributing to global warming. Many strategies to reduce emissions are targeting the methanogens that inhabit the rumen, but such an approach can only be successful if it targets all the major groups of ruminant methanogens. Therefore, a thorough knowledge of the diversity of these microbes in different breeds of cattle and sheep, as well as in response to different diets, is required. A study was undertaken using the molecular techniques denaturing gradient gel electrophoresis, DNA cloning and DNA sequence analysis to define the extent of diversity among methanogens in ruminants, particularly Bos indicus cross cattle, on differing forages in Queensland. It was found that the diversity of methanogens in forage-fed cattle in Queensland was greater than in grain-fed cattle but there was little variability in methanogen community composition between cattle fed different forages. The species that dominate the rumen microbial communities of B. indicus cross cattle are from the genus Methanobrevibacter, although rumen-fluid inoculated digestors fed Leucaena leucocephala leaf were populated with Methanosphaera-like strains, with the Methanobrevibacter-like strains displaced. If ruminant methane emissions are to be reduced, then antimethanogen bioactives that target both broad groups of ruminant methanogens are most likely to be needed, and as a part of an integrated suite of approaches that redirect rumen fermentation towards other more useful end products.
\end{abstract}

Additional keywords: Archaea, pasture.

\section{Introduction}

Global warming due to increases in the atmospheric concentration of gases such as carbon dioxide and methane is an important issue. The generation of methane from livestock industries, and particularly from ruminants, significantly contributes to the problem. Methane's global warming potential is 23 times greater than carbon dioxide and it has been calculated that $71 \%$ of Australia's anthropogenic agricultural methane emissions (or $\sim 62.1$ million tonnes of carbon dioxide equivalents annually) is from livestock (NGGIC 2007).

Methane is a by-product from the microbial digestion of plant material by cattle and sheep. Effectively, it is wasted feed material and energy that could otherwise be available for animal production. If methanogenesis were reduced in the rumen and the carbon was captured by other mechanisms, such as reductive acetogenesis, this would represent an energetic gain of $4-15 \%$ to the animal (Nollet et al. 1997; Joblin 1999). Ruminal methane is generated by a diverse group of microorganisms within the Domain Archaea. In order to develop control mechanisms to reduce methanogenesis, it is necessary to know what diversity of methanogens are present in cattle and sheep in typical production systems in Australia. It is known that few of the dominant methanogens in the rumen have been obtained in culture and that diversity changes with dietary change, and possibly, species and breed of ruminant (Whitford et al. 2001; Wright et al.2006, 2007). To date, relatively little is known of the dominant methanogens in ruminants, particularly Bos indicus cattle in northern Australia. This paper uses culture-independent methods to analyse the dominant methanogens present in the rumen of cattle and sheep (and in in vitro fermentations initiated with rumen fluid) fed a variety of diets in northern Australia.

\section{Materials and methods}

\section{Rumen samples}

Twenty-two rumen fluid samples were collected from a variety of sources for this study including $B$. indicus cross cattle fed either Mitchell grass hay (2), rye grass hay (2), spear grass hay (2), Pangola grass hay (4), a barley-based (75\%) feedlot ration (4) or a leucaena-grass pasture mix (2). Merino wethers fed lucerne pellets (2) or fresh cut kikuyu grass (2) and two samples of fluid from a fermentor receiving Leucaena leucocephala leaf as a feedstock were collected. Samples of rumen fluid were collected either per os using a stomach tube and vacuum pump, or through a rumen canula, as previously reported (Klieve et al. 1998, 2003). Rumen fluid (50-100 mL) 
was collected and strained through nylon gauze into an openmouthed jar. From each sample, four 1-mL aliquots were placed in $1.5-\mathrm{mL}$ Eppendorf tubes and centrifuged at $15000 \mathrm{~g}$ for $15 \mathrm{~min}$. The supernatant fluid was discarded and pellets frozen and stored at $-20^{\circ} \mathrm{C}$.

\section{DNA extraction, PCR amplification and denaturing gradient gel electrophoresis (DGGE)}

DNA extraction from the pelleted materials described above was by physical disruption using a bead beater, as described by Whitford et al. (1998). The DNA extracts were used as a template for nested PCR amplification of the region spanning the V2/V3 hypervariable loops of the methanogen 16S rRNA gene. Initially, partial 16S genes of Archaea were amplified from the total genomic DNA extracted from each rumen sample using the primers Arch 46F (Ovreås et al. 1997) and Arch 1017R (Barns et al. 1994). The amplification was optimised on a Hybaid PCR machine (Hybaid, Middlesex, UK) and consisted of an initial denaturation at $95^{\circ} \mathrm{C}$ for $5 \mathrm{~min}$, followed by 30 cycles of $95^{\circ} \mathrm{C}$ for $45 \mathrm{~s}, 47.3^{\circ} \mathrm{C}$ for $45 \mathrm{~s}, 72^{\circ} \mathrm{C}$ for $45 \mathrm{~s}$, with a final elongation step consisting of $72^{\circ} \mathrm{C}$ for $5 \mathrm{~min}$. The resulting PCR product was used as template in the second (nested) PCR with the primers Arch 344F-GC (Raskin et al. 1994) and Univ522R (Amann et al. 1995). The conditions consisted of a denaturation step of $94^{\circ} \mathrm{C}$ for $3 \mathrm{~min}$; followed by 20 cycles of a $94^{\circ} \mathrm{C}$ for $30 \mathrm{~s}, 65^{\circ} \mathrm{C}$ (decreasing $0.5^{\circ} \mathrm{C}$ every cycle) for $30 \mathrm{~s}$ and $72^{\circ} \mathrm{C}$ for $30 \mathrm{~s}$; the next 15 cycles consisted of $94^{\circ} \mathrm{C}$ for $30 \mathrm{~s}, 55^{\circ} \mathrm{C}$ for $30 \mathrm{~s}$ and $72^{\circ} \mathrm{C}$ for $30 \mathrm{~s}$ followed by an elongation step of $72^{\circ} \mathrm{C}$ for $10 \mathrm{~min}$. All PCR reactions were a total volume of $50 \mu \mathrm{L}$ consisting of $10 \mu \mathrm{mol} / \mathrm{L}$ of each primer, $200 \mu \mathrm{mol} / \mathrm{L} \mathrm{dNTPs}$, and $1 \mathrm{U}$ of FastStart Taq in the supplied buffer (Roche Diagnostics, Mannheim, Germany).

DGGE was performed on a BioRad DCode system (BioRad, Hercules, CA, USA) to separate the PCR products into a profile representing the diversity of methanogens present in the samples. PCR products were loaded onto a DGGE gel with $8 \%$ acrylamide and $30-60 \%$ formamide/urea gradient. Gels were electrophoresed at $100 \mathrm{~V}$ for $18 \mathrm{~h}$ in $0.5 \times$ TAE (Tris-acetate, $0.04 \mathrm{~mol} / \mathrm{L}$; EDTA, $0.001 \mathrm{~mol} / \mathrm{L}$ ) buffer, at $60^{\circ} \mathrm{C}$. Following electrophoresis, the gel was silver stained to visualise the DNA (Kocherginskaya et al. 2005) and images of the gels were obtained by scanning using a flatbed scanner.

\section{Clone libraries}

Clone libraries of the primary PCR products of each sample were produced using the TA Cloning Kit (Invitrogen, Carlsbad, CA, USA), following the manufacturer's instructions. Plasmid DNA containing a copy of the original product was extracted from the clones using the QIAprep Spin Miniprep Kit (Qiagen, Doncaster, Vic., Australia). The cloned insert was amplified from the plasmid and run on a DGGE gel alongside the DGGE banding profile from the animal to identify the band in the profile corresponding to the clone.

\section{DNA sequencing and analysis}

Sequencing of PCR amplified 16S rRNA genes was performed using the ABI Prism Dye Terminator Cycle Sequencing Ready Reaction Kit Version 3.1 with Amplitaq DNA Polymerase
FS and a model 373A DNA sequencing system (PE Applied Biosystems Inc., Foster City, CA, USA) at the Griffith University DNA Sequencing Facility (Brisbane, Qld, Australia). All procedures were performed according to the manufacturers' protocols. Gene sequences were compared with GenBank, EMBL, and DBJJ non-redundant nucleotide databases using the gapped basic local alignment search tool database search program (Altschul et al. 1990) at the National Centre for Biotechnology Information (Bethesda, MA, USA). Phylogenetic analysis followed the protocols described by Klieve et al. (2007).

\section{Results and discussion}

The DGGE banding profiles of methanogen populations in the rumen of the animals examined are presented in Fig. 1. The profiles from $B$. indicus cross cattle being fed the various forages showed a diverse population of methanogens present with between six and eight bands visible (lanes 1-9 and 20-22). However, despite the large variation in diet quality and forage type (viz. leucaena-grass pasture mix cf. rye grass hay cf. spear grass hay) there was very little difference among the DGGE profiles produced from all these animals, suggesting that they all harboured similar methanogen communities. The rye grass-fed $B$. indicus cross animal did have a band present in the upper region of its DGGE profile, which migrated to the same level as band $\mathrm{F}$ found in the L. leucocephala leaf-fed fermenter samples but its identity needs to be confirmed by sequencing. Sheep fed forage (lucerne or kikuyu grass (lanes 12-15) had similar profiles to the $B$. indicus cross steers except that they had more bands in the upper regions of the gel, particularly those sheep fed lucerne (up to 12). This pattern is indicative of there being species present with a greater $\mathrm{A}$ : T base content in the $16 \mathrm{~S}$ rRNA encoding gene (because the amplicons were denatured at a lower concentration of denaturant). Whether these differences can be attributed to host-animal differences with respect to eating behaviour and/or rumination, or whether legumes like lucerne provide greater amounts of pectins and other materials that can also support methanogen growth remains to be determined. Unlike the cattle and sheep on forage diets, the profiles from $B$. indicus cattle on grain (lanes 16-19) were different to those on forage and varied considerably between animals. An exception was animal 3665 (lane 17), which had a profile similar to some animals on pasture (lanes 20-21). The profiles were also simplified with the total number of bands in the profile reduced to three or four and only one or two main bands per animal. It would seem that grain feeding reduces the species diversity of methanogens in cattle and increases species specificity between individual cattle. Finally, the two leucaena fermentor samples produced methanogen profiles that were entirely different to all other samples and were restricted to three bright bands of high $\mathrm{A}: \mathrm{T}$ content. It is suspected that the $100 \%$ leucaena diet fed to the fermentor and the conditions in terms of feeding rate and retention time, exerts a strong selection pressure on resident populations and those normally present with other forage diets are displaced.

A total of 86 clones were obtained from seven of the samples and 39 clones representing DGGE bands of interested were sequenced. The identity of species represented in the DGGE banding profiles and the genetic relationship between cloned 




Fig. 1. Methanogen denaturing gradient gel electrophoresis profiles from Bos indicus cross steers fed Mitchell grass hay (lanes 1 and 2), rye grass hay (lanes 3 and 4), spear grass hay (lanes 5 and 20), Pangola grass hay (lanes 6, 7, 8 and 9), a barley-based feedlot ration (lanes 16, 17, 18 and 19) or leucaena (lanes 21 and 22); Merino wethers fed lucerne pellets (lanes 12 and 13) or fresh cut kikuyu grass (lanes 14 and 15);

methanogen sequences and their nearest cultured relatives is presented in Table 1. Despite the variety of cattle and sheep and the diets that were fed in this study, all of the gene sequences from the DGGE and clone libraries produced from these animals belonged within the genus Methanobrevibacter and were closely matched to cultured methanogens. Two clonal sequences were identical to previously isolated methanogens and the most distantly related sequence was still $97 \%$ similar to the sequence from a culturable methanogen. The dominance of Methanobrevibacter in the rumen of domestic ruminants is in accord with other recent studies in Western Australia and Canada (Wright et al. 2004, 2007) but contrasts with the only other report from Queensland (Wright et al. 2006), where Methanobrevibacter sequences accounted for $9 \%$ of total clones sequenced from the ruminal contents of adult sheep. From the samples examined in the present study, the only anomalies to the finding of Wright et al. (2006) were the sequences from the leucaena-fed fermentor where both sequences were most closely related to the human intestinal methanogen, Methanosphaera stadtmanae (Fricke et al. 2006). Sequences related to this species have also been identified previously from cattle, particularly in Canada (Whitford et al. 2001; Wright et al. 2007). Interestingly, M. stadtmanae is incapable of growth (and methane production) solely from carbon dioxide and hydrogen, using the methanol released during the fermentation of pectins as its primary carbon source for growth (Fricke et al. 2006). Whether these 'unusual' methanogens identified from the fermentors share

Table 1. Nearest cultivable genetic relatives to cloned methanogen sequences represented in denaturing gradient gel electrophoresis (DGGE) banding profiles

\begin{tabular}{lccll}
\hline $\begin{array}{l}\text { DGGE band } \\
\text { designation }\end{array}$ & $\begin{array}{c}\text { No. of clones } \\
\text { sequenced }\end{array}$ & $\begin{array}{c}\text { No. of bases } \\
\text { sequenced }\end{array}$ & Closest culturable relative (\% similarity) & Reference \\
\hline A & 6 & 950 & Methanobrevibacter sp. 1Y (99.5\%) & Rea et al. (2007) \\
B & 4 & 955 & Methanobrevibacter sp. SM9 (98\%) & Skillman et al. (2006) \\
C & 9 & 950 & Methanobrevibacter sp. Z8 (100\%) & Wright and Pimm (2003) \\
D & 3 & 951 & Methanobrevibacter sp. ZA-10 (99\%) & Wright and Pimm (2003) \\
E & 3 & 952 & Methanosphaera stadtmanae DSM3091 (96\%) & Fricke et al. (2006) \\
F & 2 & 953 & M. stadtmanae DSM3091 (96\%) & Fricke et al. (2006) \\
J & 4 & 942 & Methanobrevibacter sp. NT7 (97\%) & Skillman et al. (2006) \\
K & 8 & & Methanobrevibacter sp. AbM4 (100\%) & Jarvis, Skillman, Stroempl, Naylor, \\
& & & & Joblin and Moore (unpubl. data). \\
& & & &
\end{tabular}


similar characteristics remains to be determined. The results do suggest, however, that other types of methanogens can arise if the growth potential of the Methanobrevibacter types is negatively affected.

In conclusion, the diversity of methanogens in forage-fed $B$. indicus cross cattle in Queensland appears greater than in grain-fed cattle. There is little variability in methanogen community composition between cattle fed different forages but considerable variability between animals fed grain. Like humans, and ruminants in other environments, the species that dominate the ruminal ecosystem of $B$. indicus cross cattle are from the genus Methanobrevibacter. However, the results with the rumen-fluid inoculated fermentors revealed the presence of other, not-yet cultured types of methanogens, which become more noticeable when conditions do not favour the growth of the Methanobrevibacter types and (or), are more favourable for these unusual methanogens. Bioactives that target both groups of methanogens will need to be developed.

\section{Acknowledgements}

The financial assistance of the Cooperative Research Centre for Beef Genetic Technologies is gratefully acknowledged. Gratitude is also extended to Mark Morrison (The Ohio State University, and CSIRO Australia) for his support and contributions to the preparation of this manuscript.

\section{References}

Altschul SF, Gish W, Miller W, Myers EW, Lipman DJ (1990) Basic local alignment search tool. Journal of Molecular Biology 215, 403-410.

Amann RI, Ludwig W, Schleifer KH (1995) Phylogenetic identification and in situ detection of individual microbial cells without cultivation. Microbiological Reviews 59, 143-169.

Barns SM, Fundyga RE, Jeffries MW (1994) Remarkable archaeal diversity detected in a Yellowstone national park hot spring environment. Proceedings of the National Academy of Sciences of the United States of America 91, 1609-1613. doi: 10.1073/pnas.91.5.1609

Fricke WF, Seedorf H, Henne A, Kruer M, Liesegang H, Hedderich R, Gottschalk G, Thauer RK (2006) The genome sequence of Methanosphaera stadtmanae reveals why this human intestinal archaeon is restricted to methanol and $\mathrm{H}_{2}$ for methane formation and ATP synthesis. Journal of Bacteriology 188, 642-658. doi: 10.1128/ JB.188.2.642-658.2006

Joblin KN (1999) Ruminal acetogens and their potential to lower ruminant methane emissions. Australian Journal of Agricultural Research 50, 1307-1313. doi: 10.1071/AR99004

Klieve AV, Holroyd RG, Turner AF, Lindsay JA (1998) Rumen bacterial and protozoal populations in cattle being relocated in tropical Queensland. Australian Journal of Agricultural Research 49, 1153-1159. doi: 10.1071/A97164

Klieve AV, Hennessey D, Ouwerkerk D, Forster RJ, Mackie RI, Attwood GT (2003) Establishing populations of Megasphaera elsdenii YE 34 and Butyrivibrio fibrisolvens YE 44 in the rumen of cattle fed high grain diets. Journal of Applied Microbiology 95, 621-630. doi: 10.1046/j.1365-2672.2003.02024.x
Klieve AV, O'Leary MN, McMillen L, Ouwerkerk D (2007) Ruminococcus bromii, identification and isolation as a dominant community member in the rumen of cattle fed a barley diet. Journal of Applied Microbiology 103, 2065-2073. doi: 10.1111/j.1365-2672.2007.03492.x

Kocherginskaya SA, Cann IKO, Mackie RI (2005) Denaturing gradient gel electrophoresis. In 'Methods in gut microbial ecology for ruminants'. (Eds HPS Makkar, CS McSweeny) pp. 119-128. (International Atomic Energy Agency, Springer Academic Press: Amsterdam)

NGGIC (2007) 'National greenhouse gas inventory 2005 with methodology supplement.' (Environment Australia: Canberra)

Nollet L, Demeyer D, Verstraete W (1997) Effect of 2-bromoethanesulfonic acid and Peptostreptococcus productus ATCC 35244 addition on stimulation of reductive acetogenesis in the ruminal ecosystem by selective inhibition of methanogenesis. Applied and Environmental Microbiology 63, 194-200.

Ovreås L, Forney L, Daae FL, Torsvik V (1997) Distribution of bacterioplankton in meromictic Lake Sælenvannet, as determined by denaturing gradient gel electrophoresis of PCR-amplified gene fragments coding for the 16S rRNA. Applied and Environmental Microbiology 63, 3367-3373.

Raskin L, Stromley JM, Rittmann BE, Stahl DA (1994) Group-specific 16S rRNA hybridization probes to describe natural communities of methanogens. Applied and Environmental Microbiology 60, 1232-1240.

Rea S, Bowman JP, Popsvski S, Pimm C, Wright A-DG (2007) Methanobrevibacter millerae sp. nov. and Methanobrevibacter olleyae sp. nov., methanogens from the ovine and bovine rumen that can utilize formate for growth. International Journal of Systematic and Evolutionary Microbiology 57, 450-456. doi: 10.1099/ijs.0.63984-0

Skillman LC, Evans PN, Strompl C, Joblin KN (2006) 16S rDNA directed PCR primers and detection of methanogens in the bovine rumen. Letters in Applied Microbiology 42, 222-228. doi: 10.1111/ j.1472-765X.2005.01833.x

Whitford MF, Forster RJ, Beard CE, Gong J, Teather RM (1998) Phylogenetic analysis of rumen bacteria by comparative sequence analysis of cloned 16S rRNA genes. Anaerobe 4, 153-163. doi: 10.1006/anae.1998.0155

Whitford MF, Teather RM, Forster RJ (2001) Phylogenetic analysis of methanogens from the bovine rumen. BMC Microbiology 1, 1-5. doi: 10.1186/1471-2180-1-5

Wright ADG, Pimm C (2003) Improved strategy for presumptive identification of methanogens using $16 \mathrm{~S}$ riboprinting. Journal of Microbiological Methods 55, 337-349. doi: 10.1016/ S0167-7012(03)00169-6

Wright ADG, Williams AJ, Winder B, Christophersen C, Rodgers S, Smith K (2004) Molecular diversity of rumen methanogens from sheep in Western Australia. Applied and Environmental Microbiology 70, 1263-1270. doi: 10.1128/AEM.70.3.1263-1270.2004

Wright ADG, Toovey AF, Pimm CL (2006) Molecular identification of methanogenic archaea from sheep in Queensland, Australia reveal more uncultured novel archaea. Anaerobe 12, 134-139. doi: 10.1016/ j.anaerobe.2006.02.002

Wright ADG, Auckland CH, Lynn DH (2007) Molecular diversity of methanogens in feedlot cattle from Ontario and Prince Edward Island, Canada. Applied and Environmental Microbiology 73, 4206-4210. doi: 10.1128/AEM.00103-07

Manuscript received 22 January 2008, accepted 13 April 2008 